\title{
English 2.0: Learning and Acquisition of English in the Networked Globe with the Connectivist Approach
}

\author{
Aras Bozkurt \& Murat Ataizi \\ Anadolu University, Turkey
}

\begin{abstract}
English is one of the most spoken languages in the world and widely accepted as a foreign language in many parts of the world. However, though there has been a high demand for English as a foreign language in the $21^{\text {st }}$ century, it has still been taught or learned through traditional methods and conventional pedagogical approaches. In the digital age, learner characteristics, learning environments, and learner needs have significantly changed and new pedagogical approaches or learning systems have emerged as a natural result of the paradigm shift. In this article, these changes were explained and suggestions were made for foreign language learning and acquisition based on the networked learning and the connectivist approach to learning.
\end{abstract}

Keywords: English as a foreign language; EFL; Web 2.0, Connectivism; Network based learning; New pedagogy

\section{Introduction}

In the global networked world of the 21st century, English is acknowledged as lingua franca of the globe and World Wide Web. As a powerful language with which knowledge is created, articulated or exchanged, English is also one of the robust dynamics of globalization as it functions as an international language to bridge nations and unite the globe. Due to these reasons, English is presently taught in educational institutions and learned by individuals as a foreign/second language (EFL) in many parts of the world. Even though English is widely accepted as a foreign language and there is a great demand to learn it, individuals generally use conventional methods (based on knowledge transmission and teaching rather than exploring and learning) for language learning and acquisition. On the other hand, with the rise of the networked technologies, especially Web 2.0 tools and services, premising innovative pedagogical practices have been put in practice to be able to provide efficient, effective, and engaging learning experiences.

\section{Methodology}

For this research, traditional (narrative) review method was used. Traditional literature reviews are beneficial as they provide a much-needed bridge between the vast and scattered assortment of articles on a topic (Baumeister \& Leary, 1997). This type of review studies are also beneficial in terms of bringing the readers up-to-date with current literature on a topic and form the basis for another goal, such as the justification for future research in the area (Cronin, Ryan, \& Coughlan, 2008) and valuable when one is attempting to link together many 
studies on different topics, either for purposes of reinterpretation or interconnection (Baumeister \& Leary, 1997). Its primary purpose is to provide the reader with a comprehensive background for understanding current knowledge and highlighting the significance of new research. In addition, these kinds of reviews can inspire research ideas by identifying gaps or inconsistencies in a body of knowledge, thus helping the researcher to determine or define research questions or hypotheses (Cronin et al., 2008). On this basis, the purpose of this article is to summarize and synthesize distributed research findings regarding connectivism, Web 2.0 tools and services in language learning and acquisition processes.

\section{Web 2.0: Here and Now}

In the digital knowledge age, revolutionary changes have been witnessed by the globalized society. Computers, the Internet, Web, and information and communications technologies (ICT), which are some of the global actors in the current transformation age, gave birth to the digital age. Technological innovations including software and hardware created a revolutionary new medium for communication opportunities (Harrison \& Barthel, 2009) and this medium has begun to be exploited by educators and learners to augment their learning environments with digital technologies (Motteram, 2013).

In 2004, the idea of Web as a platform arose (O'Reilly, 2005) with many attributes it has in its nature. In contrast to traditional online learning environments, Web 2.0 tools and services, which are driven by user contributions and interactions, encourage social and active learning, and support social connectivity (Ajjan \& Hartshorne, 2008; Chen, Hwang, \& Wang, 2012). Web 2.0 saliences because of some characteristics like creation, refinement, and distribution of shared content (Selwyn, 2007), cooperation and collaboration of individuals (McLoughlin \& Lee, 2007) in an engaging environment which is all about harnessing collective intelligence (O'Reilly \& Battelle, 2009). Web 2.0 as a platform giving learners more choice (Stanley, 2013), enables creating collaborative learning environments that foster meaningful learning ( $O^{\prime}$ Reilly, 2005). On this basis, traditional education environments cannot be regarded as the only places in which knowledge resides anymore (Laakkonen, 2011).

As the globe is transforming a digital change presently, not only technologies but also individuals, society and tools we use go through this change. Society, the living network, has responded to these changes and a collective knowledge generation society has emerged whose members are consuming, producing, and remixing knowledge. In this society, a new generation, grown up in technology and web culture was born. Netizens (Hauben \& Hauben, 1997) or digital natives (Prensky, 2001) is the generation that internalizes technology as a routine of their casual life (Bozkurt, 2013). This generation has a tendency to use technology in many parts of their life including education. As a natural result of this radical change in profiles of today's generation and their perspectives regarding education, learners need new learning environments and tools that they can adopt easily.

New opportunities and premises that were provided by Web 2.0 affected the pedagogy and enforced it to adapt itself into the digital age. As a result of this need, Bloom's taxonomy was updated and definition of higher order thinking was revised according to new learning paradigms. Anderson and Krathwohl (2001) first revised Bloom's taxonomy and then Churches (2008) updated this revision for the digital age. According to the digital version of Blooms taxonomy, six cognitive processes updated from lower to higher order thinking skills (remembering, understanding, applying, analyzing, evaluating, and creating). According to the 
new taxonomy, what determines cognitive level is not the tool itself, but how the technology is used (Munzenmaier \& Rubin, 2013). In other words, revised skills in Bloom's Digital Taxonomy emphasize active participation and meaningful learning by using digital technologies.

All these previously mentioned changes reasoned the need to explain learning on networks and corresponding applications. Rapidly and constantly changing information, networked society and Web culture, and change in learners' needs and preferences required a new learning theory for the digital age.

\section{Language Learning and Relevant Theories}

In order to understand language learning on networks with the connectivist approach and relate them with current concepts, we need to first examine the history of learning theories briefly. Behaviorism, cognitivism, and constructivism are three dominant learning approaches that have influenced the study of learning so far. According to behaviorism, which ignores internal processes, learning is a mechanical process of associating the stimulus with response. Repeated experiences with reward and punishment play a key role and learners need reinforcement to progress. Learning is observable and can be measured. Cognitivism, as a response to behaviorism, focuses on internal learning processes and explains how information is processed to produce learning. In cognitivism, learners are active, and input is processed through internal ways and stored to be retrieved when needed. Constructivism, as a response to behaviorism and cognitivism (objectivism), focuses on experiences. According to this theory, learners construct knowledge through their own experiences (Simsek, 2000). Behaviorism, cognitivism and constructivism have one thing in common, they all claim that learning is mostly a biological process and it occurs in the human brain.

In sum, "behaviorism challenged the idea that knowledge was metaphysical. Cognitivism brought to light what could not be seen: the inner workings of the mind. Constructivism held that learning was shaped by individuals based on experience, thoughts, and interactions" (Carver, 2012). However, we still study and learn about how people learn as everything around us is advancing constantly.

Within this perspective, learning theories should be considered as "building upon (and reacting to) one another, enhancing and advancing our knowledge. We might think of spirals of knowledge, aggregating, advancing, and improving over time" (Harasim, 2012 p.10). As a further remark, one has to note that none of these learning theories try to rule out or surpass one another; conversely, they approach learning from different perspectives and fill in the gaps of each other on theoretical ground.

Therefore, different theories should be applied in language learning for different learning styles and learner needs. According to their needs and preferences, language learners will "choose an appropriate strategy to meet their learning needs" (Ally, 2004 p.19) in different situations for different objectives. On the one hand, new technologies enable us to re-evaluate current educational practices, trigger new teaching approaches, and open new pathways of learning (Alm, 2009). On the other hand, netizens as language learners use networks as a common learning platform. Nevertheless, conventional theories cannot sufficiently explain how learning occurs on networks. 


\section{Connectivism: Language Learning and Acquisition on Networks}

Connectivism as a learning theory of digital age explains how learning occurs throughout networks (Downes, 2012; Siemens, 2004). In contrast to conventional learning theories, connectivism which was born in a digital age claims that knowledge is distributed across a network of connections, and therefore learning consists of the ability to construct and traverse those networks (Downes, 2012). According connectivism, learning occurs with the interaction of the individual on networks. The strength of the tie and level of interaction defines the magnitude of learning. Kop (2011) states that rather than transferring the knowledge, learning involves active engagement of the learners by communicating through networks with the learning sources. Learners on networks who are autonomous, self-directed, and self-regulated create their own learning environment according to their own learning needs and goals.

English as a foreign language and lingua franca can be learned in formal settings and can be acquired in informal and non-formal learning environments. According to Warschauer and Meskill (2000), language educators should help learners gain apprenticeship into new discourse communities, and this can be done by providing opportunities for authentic and meaningful interaction both within and outside the classroom for their own social, cultural, and linguistic exploration. "Language learners and teachers have sensed the convenience and potential of the new learning environments in terms of improved access to and delivery of language learning experiences" (White, 2003 p.247) and started to exploit them fully. Connectivist approach in structured (formal) learning settings offers great assistive tools that can foster learning process. As a medium in semi-structured (informal) or non-structured (nonformal) learning environments, connectivism offers a learning approach similar to natural language acquisition based on connecting and meaning making. Therefore, connectivism has a vital role both in learning and acquisition process.

There are two different approaches in foreign language acquisition: Naturalistic and instructed foreign language acquisition (Ellis, 1994). Naturalistic approaches explain language acquisition through communication and social interaction, while instructed approaches explain language acquisition through study, help of instructor and other assistive materials. Connectivist approach complies with both of these approaches. For instructed approach, Web 2.0 platform, tools and services can be used to assist formal learning and to carry learning beyond the classroom walls. Web 2.0 also eliminates the deficiencies of teacher centered instructed approaches by giving learners more autonomy and by meeting their individual needs. On the other hand, for naturalistic approaches, Web 2.0 platform, tools and services can be used for self-regulated and self-directed learning. Web as a primary source of the knowledge presents a vast amount of knowledge, communication, and practice opportunities. Language learning through naturalistic approaches using Web 2.0 resembles to first language acquisition. Learners explore language on networks and makes meaningful connections to practice their language skills and improve knowledge areas.

\section{Digital Language Learning Ecosystem}

A natural ecosystem is a biological community of interacting organisms and their physical environment (Uden, Wangsa, \& Damiani, 2007). As a metaphor to describe an environment for learning, a learning ecology is described as an open, complex adaptive system comprising elements that are dynamic and interdependent (Brown, 2000). As an extension in Web platforms, a digital ecosystem is a self-organizing digital infrastructure focused on creating a 
digital environment that supports cooperation, knowledge sharing, development of open and adaptive technologies as well as evolutionary learning models (Uden, Wangsa, \& Damiani, 2007). A successful learning ecology offers individuals a ubiquitous learning environment. Students have open and immediate access to the ecology where they can search, locate, and quickly access elements of learning that address their immediate needs. Students also use the ecology to construct and organize personalized and unique interactions with the content (Richardson, 2002).

Social software, including but not limited to Web 2.0 tools and services, help individuals to architect their own learning ecosystem designed exactly for their needs. From a holistic perspective, a digital language learning ecosystem appears as a system that provides seamless learning opportunities among formal, informal, and non-formal learning domains.

\section{English 2.0 as a New Concept}

Information and communication technologies are part of the broader ecology of life and our communication preferences are changing their media from more traditional ones to digital ones (Warschauer \& Meskill, 2000). The globe is experiencing a rapid change and becoming more connected each passing day, and this requires a necessity to reflect these changes into learning practices (Taranto, Dalbon, \& Gaetano, 2011). English as the language of the world (Jenkins, 2003; Jenkins et al., 2009) accepted this reality in the networked world with Web 2.0 tools and services. Web 2.0 not only changes what we know in the classrooms, but also offers effective opportunities for English language acquisition (de Ramirez, 2009) and learning. Web 2.0 has potential for language learners to develop listening, speaking, reading, and writing skills actively (Morgan, 2012), and to improve their grammar and vocabulary knowledge.

At this point language acquisition and learning can be defined as two distinct terms. In our framework, language acquisition is the process of mastering a language through natural ways: communicating and exposing language in a natural context. Diversely, language learning refers to the process of mastering a language in a more planned way: practicing and using language in a planned or designated context. Even though these terms intersect and have blurred borders, language acquisition is generally informal or non-formal while language learning is relatively more formal.

In the first place, language learning and teaching systems reacted to these changes and many practices were applied into language learning area using computers and Web 1.0 as a one-way delivery tool. Behaviorist, cognitivist, and constructivist approaches integrated themselves well into technology as a tool concept in learning and teaching processes. On the other hand, advent of the ubiquitous computing and Web 2.0 with dynamic structure changed the rules of the game. Technology as a tool concept turned into technology as an environment and platform in English learning and acquisition practices.

\section{Practicing Language Skills and Areas in a Networked World}

Currently, English stands as the most spoken language on Web as well as the lingua franca in the real world. According to W3Techs' (2013) daily updated data, 56\% of the entire World Wide Web use English as the content language, which is a massive source of knowledge for English language learners. Web 2.0 tools and services provide opportunities to harness the 
information on Web and information collected in real life. In order to overcome the limitations of existing models of teaching and learning, and exploit more fully the affordances and potential for connectivity enabled by social software tools (McLoughlin \& Lee, 2007), not to be out of sync with the technology available to students in the reality (Hardman \& Carpenter, 2007), to meet language learners' needs in the digital age, not to fall behind of the contemporary education perception and provide learning centered opportunities, these new emerging technologies should be applied in language learning in formal, informal, and nonformal settings. Web 2.0 tools and services with many advantages use them in language learning, "emphasis active participation, connectivity, collaboration and sharing of knowledge and ideas among users" (McLoughlin \& Lee, 2007 p.665). For an individual no matter in formal, in-formal or non-formal context, the missing point is to access to other language users with whom they can practice. Technology with rich communication opportunities in different forms (oral or written) helps to language users to overcome this limitation and let them use their target language for a mutual interest (Pim, 2013).

In English language, there are four skills and two areas (Figure 1). Reading, writing, listening, and speaking are the basic skills needed to communicate in target language. These skills are not isolated from each other; they facilitate learning all together and have an interchangeable relationship. Grammar and vocabulary are the areas needed to improve language skills and to use target language more effectively and appropriately. All four skills and two areas are necessary for using language and developing language proficiency.

\section{Language Learning and Acquisition through Web 2.0}

In this part of the article, we offer some Web 2.0 tools and services. Even though there are many others, we explained basic tools and services as examples.

\section{Listening Skill: Podcast, Online Radios, Vlogs, and VolP}

Listening is a spoken receptive skill. To practice and improve listening skill, podcasts provide materials in a wide range. Learners can choose content of the listening material according to their needs or interests. Podcasts and other listening materials are also helpful to brush up grammar, vocabulary (Pegrum, 2009b), and dictation (Lu, 2009). As a rich source of authentic oral models via vocal materials, network based environments help learners with acquisition, pronunciation, and reinforcement of new vocabulary (Pim, 2013).

Vlogs like YouTube provides sound and dynamic visuals together, which give learners an opportunity to see gestures, mimics or the environment to make meaningful connections with the content. Another advantage of the Vlogs is that they allow learners to see mouth shapes, which is important to produce accurate sounds. Some of them have subtitle support which helps learners to catch the content simultaneously and to see differences in written and spoken form of the target language. Recorded listening materials are also advantageous as learners repeat, regulate speed and stop whenever they need. 


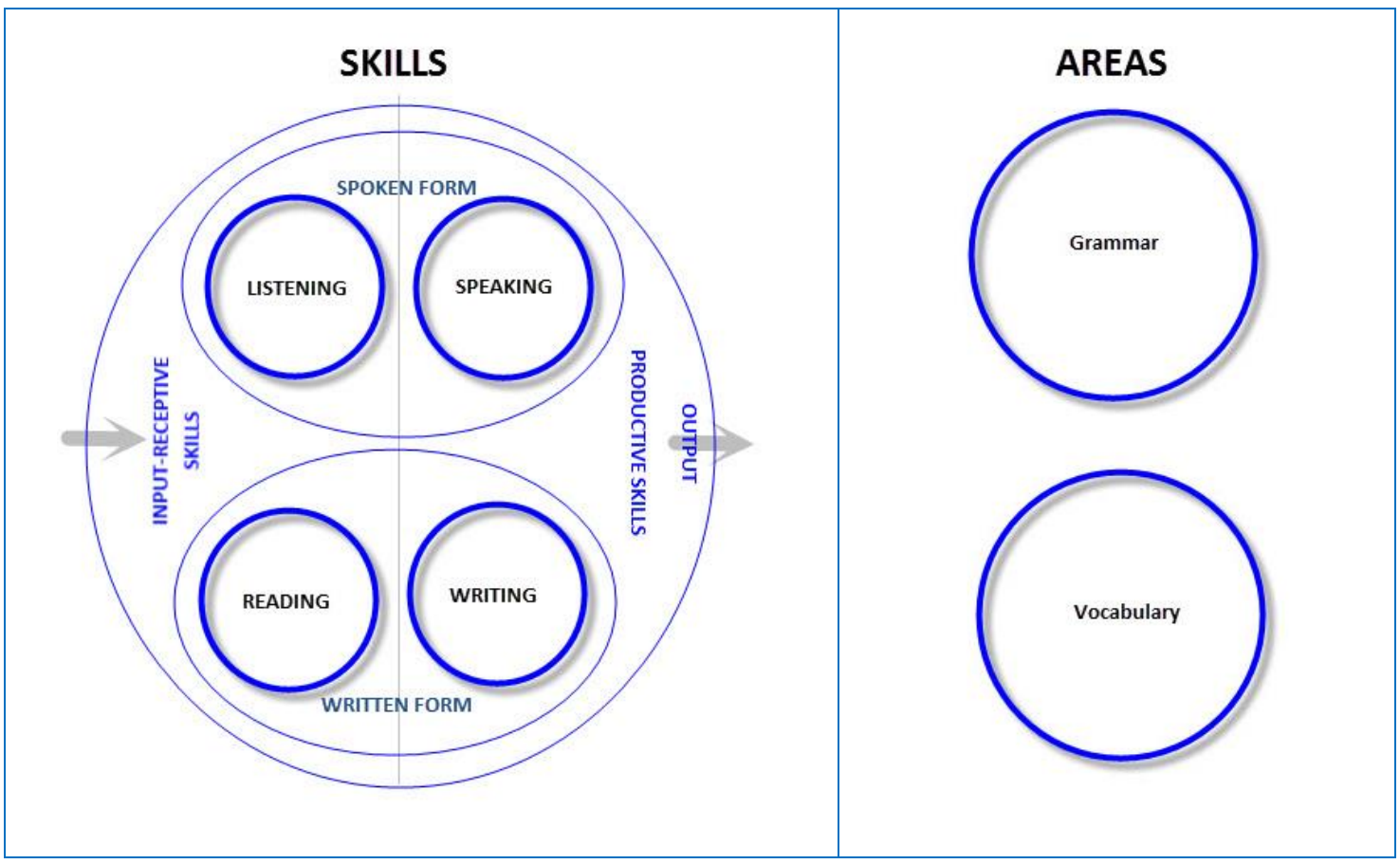

Figure 1. Language Skills and Areas

VoIP services like Skype provides real time interaction and feedback and one of the most effective tool for listening skill. Online radios are great as learners engage their listening skill constantly. Learners can be active or passive while listening to online radios and when there is something engaging and they can switch on their attention.

\section{Speaking Skill: VolP and Vlogs}

Speaking is a spoken productive skill. One of the basic assumption in language learning and acquisition is improving communication skill through actual linguistic communication with a native speaker of the target language (Mullen, Appel, \& Shanklin, 2009) and VolP services used in many different ways for formal and informal language learning and teaching (Kern, 2013) to access native speakers of target language.

VoIP tools provide synchronous interaction. Learners use language just like they do in the real world. Conversations through VoIP services like Skype can be one-to-one or group chat. Prompt feedbacks from other learners help the learners to evaluate themselves. As well as practicing their speaking skill, they can also change their cultural experiences through communication (Benito-Ruiz, 2009) and extend borders of classroom beyond walls, engage students to communicate with an authentic audience in an authentic atmosphere by providing real time communication (Bossa, Stevens, \& Tawel, 2012).

Vlogs like YouTube facilitate self-evaluation to learners. Learners can record their conversation and playback to see how they speak. On web 2.0 platform, while sync tools assist fluency and flow, async tools improve accuracy. In practice, based on speaking skill and using VolP services, educators and learners should decide whether their aim is fluency or accuracy and then plan, implement and evaluate process in terms of pedagogy (Kern, 2013). By using these tools, learners can evaluate themselves and understand how clear, fluent and accurate they speak. 
Through karaoke-style approach, learners may visualize rhymes and can imitate mouth movements to develop phonetic accuracy (Pim, 2013).

One challenge of these VolP services is learners being shy or having lack of confidence in their language abilities while using VoIP tools, which limits conversational exchange and causes inadequacy to invest equal effort as well as time and use of the two languages that result in a conversation to be short lived (Mullen et al., 2009).

\section{Reading Skill: Blogs, RSS, and Mashups}

Reading is a written receptive skill. For this skill, filtering the content poses an important issue. On networks, there are many written sources and to learn from them to improve learners target language requires enhanced readership (Sykes et al., 2008). On the other hand, we offer RSS feeds to practice and improve this skill. Rather than jumping into every written material, learners can arrange reading materials according to their interests and proficiency levels.

Following and reading blogs are another effective way for reading skill. Reading organized content is also helpful to see flow and structure both for reading and writing activities. Mashups are also beneficial as learners can combine different media and create something new according to their need. The biggest limitation of these tools is quality of the content source.

\section{Writing Skill: Blogging, Microblogging, and Wikis}

Writing is a written productive skill. Blogging is a great way to practice writing skill, reach an audience and it is also effective in terms of self-expression and reflecting thoughts. Blogs are also good for classwork as an ongoing record is always displayed at the top of the page (Stanley, 2013).

Wikis are another tool to improve collaborative and critical writing skill and help language users learn how to organize their writing. Wikis are useful for process writing (Wang \& Heffernan, 2009), joint content creation (Laakkonen, 2011) and with its flexible structure good for project works (Stanley, 2013). Wikis are also important as learners get feedback from other authors.

Microblogging is another way for improving creative writing skills as it limits the length of the sentence(s). Micro blogging is suitable for new language learners as it doesn't require advance proficiency in language. Besides, they are suitable for discussing a topic and sharing thoughts with the crowd on networks.

All in all, Wikis are ideal for academic writing, blogs are ideal for free writing, and micro blogs are ideal for creative writing skill. Blogs are appropriate mediums for one-to-many interaction while wikis are suitable for many-to-many interaction. The limitations of these tools are that sometimes written content may be superficial and the content quality may be low.

In addition to these advantages, spelling and grammar checking tools will be beneficial to correct (Davies, 2004) and learn from mistakes in a writing process. Integrated dictionaries will 
be useful for advanced learners and help them to develop their writing with many alternatives they offer (Pim, 2013).

English as a foreign language or other target languages don't consist of merely four skills and two areas. There are other areas such as pronunciation, comprehension, guessing etc. On the other hand, four skills and two areas are the fundamental domains and somehow cover every component of a language. So, in addition to these four skills, we present some helpful tools and services for grammar and vocabulary areas.

\section{Grammar: Social Networks and Social Bookmarking}

Grammar is the area based on understanding rules and relationships. Learners learn a set of rules and apply them to use language effectively. Even though there are many sites and forums covering grammar topics, we focus on Web 2.0 tools as we emphasize active participation and engagement. At this point, the key concepts concerning grammar are presenting (passive) or practicing (active) grammar.

In practicing grammar viewpoint, social networks are great medium. In social networks, there are many online groups for practicing grammar. Social networks are helpful as they provide learning grammar by cooperation, discussing and explaining with different examples in a communicative environment.

In addition to common social networks, there are social networks specially designed for language learning. These networks are also helpful to empower grammar as well as other areas and skills. Palabea, Livemocha, and Babbel networks are popular examples of this kind of social networks.

Walls, chat and message features of social network sites are other elements that have the potential to enable students to engage directly with native speakers (Pegrum 2009b) and to expose language, so the grammar structures as well as other areas and skills. Yet, style and level of the target language is crucial as learners model it.

Finally, social bookmarking is helpful to organize and classify grammar sources. Learners can create their own grammar reference book by collecting, linking, tagging, and sharing resources. Social bookmarks and tags are a way of indexing distributed knowledge that allow information linking with a social element as they are organized by people on networks (Lampe, 2006).

\section{Vocabulary: Online Dictionaries, Word Clouds, Tags, and Visual Word Maps}

Vocabulary is an area based on meaning and use of words. Online dictionaries have revaluated the use of dictionaries. Online dictionaries present meaning, pronunciation in different accents, examples in different contexts, visual representations, word origin, relevant words, synonyms, antonyms, spelling and even visual maps about the word searched less than in a second. They even let users know the trend words searched in their region.

In addition to online dictionaries, word clouds and tags are helpful to see and learn trend words about a topic or a text. It is also helpful for understanding the relevance of the words, building vocabulary, analyzing content, and brainstorming. Visual word maps present the 
searched word's relationship with other words. Visual word maps are helpful as learners are able to make meaningful connections with relevant words and it is easy to learn visualized words.

\section{Future Trends for Language Learning}

Web 1.0 refers to read only informational web (Pegrum, 2009a; 2009b) that connects information and led to development of search engines (Thomas, 2009) while Web 2.0 is readwrite social Web (Pegrum, 2009a) that connects people reinforcing the way they communicate and access their information and mediate the world through digital technologies (Thomas, 2009). Web 3.0 is semantic Web. According to Spivack (2006), Web 3.0 might be defined as a third-generation of the Web enabled by the convergence of several key emerging technology trends and it will be more connected, open, and intelligent, with semantic Web technologies, distributed databases, natural language processing, machine learning, machine reasoning, and autonomous agents.

It is clear that Web 3.0 will bring many new innovations; however, its semantic structure stands out as a dominant feature. In terms of language learning, Web 3.0 will track, record, and evaluate our activities in an interactive manner that will allow advance learning analytics. According to Johnson et al. (2013), learning analytics is an emergent field of research that aspires to use data analysis to inform decisions made on every tier of the educational system. Learning analytics will lead to an individual path for language users according to their needs and progress. The intelligent structure of the Web will decide on behalf of learners based on learner related data. It is pointed out that learning analytics will provide a higher quality personalized experience (Johnson et al., 2013) for language learners. Web 3.0 and learning analytics might be very effective as language learning and acquisition consist of different fields and areas. Language users will not need to learn what they already know; instead of this, with backs and forwards in their learning quest, they might get what they actually need: specific, targeted and process oriented language learning and acquisition.

\section{Discussion and Conclusion}

Language users of digital age are involved in activities in their routine life using Web 2.0 tools and services and they are surrounded Web-based knowledge resources chiefly in the Internet Lingua Franca which is English (Laakkonen, 2011). Though language users use Web 2.0 tools and services in their everyday life, which gives these tools an educational value (Ryan, 2007), they are still at a very preliminary stage in the educational domain and their implications for learning are largely untapped (Laakkonen, 2011). Thus, there is a trend to explore potential uses and roles of web-based technology in language teaching (Gilbert, 2013).

Lifelong learning valued informal and non-formal learning as well as formal learning. Computing, networks, and Web changed what we know and triggered a new age called as information age or digital age. In a united globalized world, English is accepted as a common language, almost the mother tongue of everyone; that is to say, as lingua franca. As a result of the increasing demand for learning English, new learning approaches and tools have emerged. Connectivism and Web 2.0 tools have been used recently and commonly for language learning and acquisition. 
Connectivism as a learning theory of digital age explains how learning occurs on networks and offers Web 2.0 tools to individuals to practice and improve their English. Web 2.0 platform, tools and services rise as the star of the 21st century with advantages such as providing active participation, cooperation and collaboration; increasing independence and autonomy; empowering creativity and connectivity; enabling personalization and customization; facilitating learning with flexible and ubiquitous opportunities and giving power to the self.

Even though Web 2.0 tools and services are effective, efficient, and engaging, it is important to know for which purposes and contexts they will be used. For language learning, Web 2.0 tools and services are great as an assistive technology; and for language acquisition, they are great as a learning environment. Secondly, individuals should raise following question before they start to use these tools for language learning or acquisiton: What is my focus? Function or form? Functional use of language generally focuses on fluency, while form focuses on accuracy. All in all, one should pay attention to deciding which tools or services to use to accommodate learners needs.

Network based connectivist approach for English language learning and acquisition supports formal learning settings, while informal and non-formal learning environments accommodate learner needs and amplify learning process. Educational institutions, language educators, and instructional designers should apply Web 2.0 technologies to be up-to-date, to provide appropriate learning opportunities to netizens and to design learning environments according to information ecology on networks. Learning or acquiring a language initially requires a need for meaningful learning. Providing tailor-made options through Web 2.0 can be first step to meet this need.

\section{References}

Ajjan, H. \& Hartshorne, R. (2008). Investigating faculty decisions to adopt Web 2.0 technologies: Theory and empirical tests. The Internet and Higher Education, 11(2), 7180.

Ally, M. (2004). Foundations of educational theory for online learning. In T. Andersen and F. Elloumi (Eds.), Theory and practice of online learning (pp.3-31). Athabasca, Canada: Athabasca University.

Alm, A. (2009). Blogging for self-determination with L2 learner journals. . In M. Thomas (Ed.), Handbook of Research on Web 2.0 and second language learning (pp.202-222). Hershey, PA: IGI Global.

Anderson, L. \& Krathwohl, D. (2001). A taxonomy for learning, teaching and assessing: A revision of Bloom's taxonomy of educational objectives. New York: Longman.

Baumeister, R. F. \& Leary, M. R. (1997). Writing narrative literature reviews. Review of General Psychology, 1(3), 311-320.

Benito-Ruiz, E. (2009). Infoxication 2.0. . In M. Thomas (Ed.), Handbook of Research on Web 2.0 and second language learning (pp.60-79). Hershey, PA: IGI Global.

Bossa, M., Stevens, V., \& Tawel, A. (2012). Ayat Al-Tawel and Maria Bossa discuss their students' collaborations between Egypt and Argentina Learning2gether podcast. Retrieved on 19 February 2015 from http://learning2gether.net/2011/06/12/ayat-altawel-and-mariabossa-discuss-their-s/ 
Bozkurt, A. (2013). Açık ve uzaktan ogretim: Web 2.0 ve sosyal aglarin etkileri [Open and distance teaching: Web 2.0 and impact of social networks]. Akademik Bilisim 2013 (ss. 649-654). Antalya: Akdeniz Universitesi. Available at: http://www.academia.edu/ 2536910/Acik_ve_Uzaktan_Ogretim_Web_2.0_ve_Sosyal_Aglarin_Etkileri

Brown, J.S. (2000). Growing up digital: How the web changes work, education, and the ways people learn. Change Magazine, March/April, 11-20.

Carver, D. (2012). Book review - Learning theory and online technologies. The International Review of Research in Open and Distance Learning, 13(4), 324-326.

Chen, Y. C., Hwang, R. H., \& Wang, C. Y. (2012). Development and evaluation of a Web 2.0 annotation system as a learning tool in an e-learning environment. Computers \& Education, 58(4), 1094-1105.

Churches, A. (2008). Bloom's taxonomy Blooms digitally. Educators' eZine. Retrieved on 19 February 2015 from http://www.techlearning.com/article/8670

Cronin, P., Ryan, F., \& Coughlan, M. (2008). Undertaking a literature review: A step-by-step approach. British Journal of Nursing, 17(1), 38-43.

Davies, N. (2004). Not just how but why: EAL and ICT in the multilingual classroom. NALDIC Quarterly 1/4. Retrieved on 19 February 2015 from http://www.naldic.org.uk/ Resources/NALDIC/docs/resources/documents/Notjusthowbutwhy.pdf

de Ramirez, L. L. (2009). Empower English language learners with tools from the Web. Thousand Oaks, CA: Sage.

Downes, S. (2012). Connectivism and connective knowledge: Essays on meaning and learning networks. Retrieved on 19 February 2015 from http://www.downes.ca/files/books/ Connective_Knowledge-19May2012.pdf

Ellis, R. (1994). The study of second language acquisition. Oxford, UK: Oxford University Press.

Gilbert, J. (2013). English for Academic Purposes. In G. Motteram (Ed.), Innovations in learning technologies for English language teaching (pp.117-144). London: The British Council.

Harasim, L. (2012). Learning theory and online technologies. New York, NY: Routledge.

Hardman, J. \& Carpenter, D. (2007). Breathing fire into Web 2.0. Learning \& Leading with Technology, 34(5), 18-21.

Harrison, T. M. \& Barthel, B. (2009). Wielding new media in Web 2.0: Exploring the history of engagement with the collaborative construction of media products. New Media \& Society, 11(1-2), 155-178.

Hauben, M. \& Hauben, R. (1997). Netizens: On the history and impact of Usenet and the Internet. Los Alamitos, CA: Wiley-IEEE Computer Society Press.

Jenkins, H., Clinton, K., Purushotma, R., Robinson, A. J., \& Weigel, M. (2009). Confronting the challenges of participatory culture: Media education for the 21st century. Cambridge: MIT Press.

Jenkins, J. (2003). World Englishes: A resource book for students. London: Routledge

Johnson, L., Adams Becker, S., Cummins, M., Estrada, V., Freeman, A., \& Ludgate, H. (2013). NMC Horizon Report: 2013 Higher Education Edition. Austin, Texas: The New Media Consortium. 
Kern, N. (2013). Technology-integrated English for Specific Purposes lessons: Real-life language, tasks, and tools for professionals. In G. Motteram (Ed.), Innovations in learning technologies for English language teaching (pp.87-116). London: The British Council.

Kop, R. (2011). The challenges to connectivist learning on open online networks: Learning experiences during a massive open online course. The International Review of Research in Open and Distance Learning, 12(3), 19-38.

Laakkonen, I. (2011). Personal learning environments in higher education language courses: an informal and learner-centred approach. In S. Thouësny \& L. Bradley (Eds.), Second language teaching and learning with technology: Views of emergent researchers (pp. 928). Dublin: Research-publishing.net.

Lu, J. A. (2009). Podcasting as a next generation teaching resource. In M. Thomas (Ed.), Handbook of Research on Web 2.0 and second language learning (pp.350-365). Hershey, PA: IGI Global.

McLoughlin, C. \& Lee, M. J. (2007). Social software and participatory learning: Pedagogical choices with technology affordances in the Web 2.0 era. ICT: Providing choices for learners and learning. Proceedings ascilite Singapore 2007 (pp. 664-675).

Morgan, L. (2012). Generation Y, learner autonomy and the potential of Web 2.0 tools for language learning and teaching. Campus-Wide Information Systems, 29(3), 166-176.

Motteram, G. (2013). Introduction. In G. Motteram (Ed.), Innovations in learning technologies for English language teaching (pp.5-13). London: The British Council.

Mullen, T., Appel, C., \& Shanklin, T. (2009). Skypebased tandem language learning and web 2.0. In M. Thomas (Ed.), Handbook of Research on Web 2.0 and second language learning (pp. 101-118). Hershey, PA: IGI Global.

Munzenmaier, C. \& Rubin, N. (2013). Bloom's taxonomy: What's old is new again. The eLearning Guild. Retrieved on 19 February 2015 from http://publicservicesalliance.org/ wp-content/uploads/2013/04/guildresearch_blooms2013.pdf

O'Reilly, T. (2005). What is Web 2.0 - Design patterns and business models for the next generation of software. Retrieved on 19 February 2015 from http://oreilly.com/web2/ archive/what-isweb-20.html

O'Reilly, T. \& Battelle, J. (2009). Web squared: Web 2.0 five years on. Retrieved on 19 February 2015 from http://assets.en.oreilly.com/1/event/28/web2009_websquaredwhitepaper.pdf

Pegrum, M. (2009a). From blogs to bombs. Crawley, Western Australia: UWA Publishing.

Pegrum, M. (2009b). Communicative networking and linguistic mashups on Web 2.0. In M. Thomas (Ed.), Handbook of Research on Web 2.0 and second language learning (pp.2041). Hershey, PA: IGI Global.

Pim, C. (2013). Emerging technologies, emerging minds: digital innovations within the primary sector. In G. Motteram (Ed.), Innovations in learning technologies for English language teaching (pp.15-42).London: The British Council.

Prensky, M. (2001). Digital natives, digital immigrants. On the Horizon, 9(5), 1-6.

Richardson, A. (2002). An ecology of learning and the role of elearning in the learning environment. Global Summit of Online Knowledge Networks, 47-51. 
Ryan, Y. (2007). Do you YouTube? Wanna come to MySpace? Musings on narcissism in the 21st century student. In First Year in Higher Education Conference, QUT Brisbane. Retrieved on 19February 2015 from http://www.fyhe.com.au/past_papers/papers07/final_ papers/Do\%20you\%20YouTube\%20_2_.pdf

Selwyn, N. (2007, October). Web 2.0 applications as alternative environments for informal learning-a critical review. In Paper for CERI-KERIS International Expert Meeting on ICT and Educational Performance (pp. 16-17). Cheju Island, South Korea.

Siemens, G. (2004). Connectivism: A learning theory for the digital age. Retrieved on 19 February 2015 from http://www.elearnspace.org/Articles/connectivism.htm

Simsek, A. (2000). Egitim iletisimi [Educational communications]. Eskisehir: Anadolu Universitesi Yayinlari (No: 1252/39).

Spivack, N. (2006). Web 3.0: The third generation of Web is coming. Retrieved on 19 February 2015 from http://lifeboat.com/ex/web.3.0

Stanley, G. (2013). Integrating technology into secondary English language teaching. In G. Motteram (Ed.), Innovations in learning technologies for English language teaching (pp.43-66). London: The British Council.

Sykes, J. M., Oskoz, A., \& Thorne, S. L. (2008). Web 2.0, synthetic immersive environments, and mobile resources for language education. CALICO Journal, 25(3), 528-546.

Taranto, G., Dalbon, M., \& Gaetano, J. (2011). Academic social networking brings Web 2.0 technologies to the middle grades. Middle School Journal, May 2011, 12-19. Retrieved on 19 February 2015 from http://cmsd.k12.pa.us/cmsd/cm_intsafe/documents/ MiddleSchoolJournalArticleMay2011.pdf

Thomas, M. (Ed.). (2009). Handbook of research on Web 2.0 and second language learning. Hershey, PA: IGI Global.

Uden, L., Wangsa, I. T., \& Damiani, E. (2007). The future of E-learning: E-learning ecosystem. In Digital EcoSystems and Technologies Conference, 2007: DEST'07 (pp. 113-117). IEEE.

W3Techs, (2013). Usage of content languages for websites. Retrieved on 19 February 2015 from http://w3techs.com/technologies/overview/content_language/all

Wang, S. \& Heffernan, N. (2009). Mobile 2.0 and mobile language learning. In M. Thomas (Ed.), Handbook of Research on Web 2.0 and second language learning (pp.472-490). Hershey, PA: IGI Global.

Warschauer, M. \& Meskill, C. (2000). Technology and second language teaching. In J. W. Rosenthal (Ed.), Handbook of undergraduate second language education (pp.303-318). London: Routledge.

White, C. (2003). Language learning in distance education. Cambridge: Cambridge University Press.

Correspondence: Murat Ataizi, Associate Professor, Department of Communication Design and Management, Faculty of Communication Sciences, Anadolu University, Yunus Emre Campus, Eskisehir, Turkey 